\title{
TB/HIV Coinfection and Other Medical Co-Morbidity in Older Adults (50 - 64 Years) in Botswana: Evidence from 2013 Botswana AIDS Impact Survey (BAIS IV)
}

\author{
Njoku Ola Ama1*, Helen Aforji Ama², Francis Nathan Okurut ${ }^{3}$ \\ ${ }^{1}$ Department of Statistics, University of Botswana, Gaborone, Botswana \\ ${ }^{2}$ Department of Educational Management, University of Botswana, Gaborone, Botswana \\ ${ }^{3}$ Department of Economics, University of Botswana, Gaborone, Botswana \\ Email: ^njoku52@gmail.com, *amano@ub.ac.bw,nneomagood@gmail.com,okurutf@mopipi.ub.bw
}

How to cite this paper: Ama, N.O., Ama, H.A. and Okurut, F.N. (2019) TB/HIV Coinfection and Other Medical Co-Morbidity in Older Adults (50 - 64 Years) in Botswana: Evidence from 2013 Botswana AIDS Impact Survey (BAIS IV). Advances in Sexual Medicine, 9, 40-51.

https://doi.org/10.4236/asm.2019.93004

Received: June 17, 2019

Accepted: July 26, 2019

Published: July 29, 2019

Copyright (c) 2019 by author(s) and Scientific Research Publishing Inc. This work is licensed under the Creative Commons Attribution International License (CC BY 4.0).

http://creativecommons.org/licenses/by/4.0/

\begin{abstract}
Background: Many older adults (50 - 64 years) in Botswana with HIV do not know they are infected with TB. Some with TB disease are unaware of their HIV status, yet HIV/TB coinfection is high. The study aims to determine the prevalence of TB among older adults with HIV, their HIV/AIDS knowledge and vulnerability to hypertension, diabetes and asthma using the 2013 BAIS IV data. Material and Methods: The BAIS IV study, from which the data for this article is derived, used a stratified two-stage probability sampling design. The first stage was the selection of 297 Enumeration Areas (EAs) as Primary Sampling Units and second stage was selection of households $(5,415)$ in the EAs. The study targeted all usual members of the selected households aged 6 weeks and above for the Biomarker or testing for HIV and those aged $10-64$ years old for the behavioral questionnaire. Results: The study shows that the older adults (50 - 64 years) with TB have a low level of education and HIV prevalence is very high ( $44 \%$ for age $50-54,40.6 \%$ for age 55 - 59 and $68.4 \%$ for age $60-64$ years). The rate of HIV/TB coinfection, $21.9 \%$, is high and prevalence of $\mathrm{TB}$ among the older adults is $8.6 \%$ (13\%, males and $5.3 \%$, females) while only $0.8 \%$ are currently on treatment. Only $67.2 \%$ know that if a pregnant mother is infected with HIV, there is a way of preventing transmission of the virus to the child. Age, level of education, marital status and employment status significantly $(\mathrm{p}<0.01)$ predict TB diagnosis and treatment. Conclusion: The study concludes that lower education seems to be an obstacle to accessing TB treatment. Therefore, older adults' awareness and knowledge of the symptoms of both diseases (TB and HIV), mode of infection and
\end{abstract}


treatment need to adequately improve through increased education to overcome health challenges when infected with asthma, diabetes and high blood pressure/hypertension.

\section{Keywords}

TB, HIV/AIDS, Older Adults, TB/HIV Coinfection, Logistic Regression

\section{Introduction}

Tuberculosis (TB) is the largest single cause of death in the setting of AIDS [1] accounting for about $26 \%$ of AIDS-related deaths [2], $99 \%$ of which occur in developing countries [3]. People living with HIV have been shown to be $16-27$ times more likely to develop TB than persons without HIV, due to their weakened immune system and any delay in diagnosing and treating the TB disease may lead to their death [4]. The WHO [1] report indicated that in 2017, one out of every three HIV-related deaths was due to TB and about half the people living with HIV who may have fallen ill with TB do not reach care.

The International Diabetes Federation (IDF) estimates that 450 million people are living with diabetes, with 5.1 million dying from it annually worldwide [5]. The prevalence of diabetes is expected to double by 2030. The prevalence of diabetes has been estimated to be between $7.7 \%$ to $20 \%$ and $5 \%$ to $8.8 \%$ for adults aged 45 years and more in Kenya and South Africa respectively [6]. In addition, more diabetic people live in urban than in rural areas [7].

Asthma is one of the most common chronic respiratory diseases and is a major public health issue globally, affecting people of all ages, genders and ethnicities. It is estimated that the number of people with asthma worldwide may be as high as 334 million according to a report from the Global Asthma Network published in 2014 [8]. A study by [9] showed that the adjusted prevalence of asthma ranged from $4.4 \%$ [95\% CI: $4.0 \%-4.8 \%$ ] in Turkey, to 6.7\% [95\% CI: $6.2 \%$ 7.2\%] in Egypt and 7.6\% [95\% CI: 7.1\% - 8.0\%] in the Gulf cluster. Prevalence was higher $(\mathrm{p}<0.0001)$ in women than men and increased with age $(\mathrm{p}<0.0001)$. Co-morbidities occurred more frequently in asthma subjects compared to the non-asthma population ( $38 \%$ vs. $15 \% \mathrm{p}<0.0001)$.

Hypertension causes over 7 million premature deaths per year and contributes to $4.5 \%$ of the total disease burden worldwide [10]. Older adults account for the bulk of hypertension-related morbidity and mortality. This is due largely to dramatically greater prevalence among the elderly [11]. Data from the National Health and Nutrition Examination Survey indicate that $70 \%$ of older adults have hypertension, compared to only $32 \%$ for adults aged 40 - 59 years [11]. Notwithstanding that hypertension is relatively easy to prevent, simple to diagnose, and relatively inexpensive to treat, it remains the second leading cause of death among Americans, and as such should rightly be called a neglected disease [12].

The Sub-Saharan Africa is the most affected region experiencing the HIV and 
TB coinfection. Approximately $86 \%$ of all deaths from HIV-associated TB observed in 2016 were found in this region [13]. There are people with HIV who do not know they are infected with TB and there are also people with TB disease who are unaware of their HIV status [14]. One of the identified prevention challenges in dealing with HIV and TB coinfection is lack of awareness of TB or HIV status which can prevent adequate treatment [14]. It is therefore necessary to test anyone who has recently received an HIV or TB diagnosis for coinfection. The Botswana 2014 Country Operational Plan Executive Summary

(https://www.pepfar.gov/countries/cop/240120.htm) showed that there has also been significant increase in HIV testing among people with TB rising from 80 percent in 2011 to 95 percent in 2012, and ART initiation among co-infected patients also increased from 45 percent in 2010 to 65 percent in 2012. How these interventions and efforts target the older adults aged 50 - 64 years is not clear. Thus, despite the tremendous effort made in diagnosing TB among HIV patients in Botswana, there is little or no documented information on TB/HIV coinfection diagnoses among the older adults (50 years and over). However, a study undertaken at Mahalapye Health Districts (MHD) from 2013 to 2015 [15] showed that $80 \%$ of all the TB patients were co-infected with HIV and of this percentage, $51.3 \%$ belonged to the age group 18 - 44 years, $26.4 \%$ belonged to the age group 45 - 64 years, and $2.8 \%$ belonged to the age group 65 years and over. This small scale study reveals great number of older adults with TB coinfection with HIV.

The older adults constitute the caregivers of relatives with HIV and TB coinfection and are, therefore, very vulnerable to TB infection [16] [17] [18]. Knowledge of their TB status is important and can help in improving their health as well as the young children in their care. It is important to determine the older adults' TB prevalence, knowledge and awareness about HIV/TB, treatment and vulnerability to non-communicable diseases for improved health as caregivers.

This study aims to determine the prevalence of TB among older adults, their HIV/AIDS situation and knowledge, and vulnerability to hypertension, diabetes and asthma using the 2013 BAIS IV data. The results of the study will inform the need for a large scale study on TB/HIV coinfection and its impact on the older adults with subsequent development of prevention care, education and training by the Public Health Department of the Ministry of Health.

\section{Material and Methods}

The 2013 BAIS IV study [19], conducted by Statistics Botswana, the national body in charge of producing all statistics in Botswana, used a stratified two-stage probability sample design. At the first stage of sampling, Enumeration Areas (EAs) were selected as Primary Sampling Units (PSUs) with probability proportional to measures of size (PPS), where measures of size (MOS) was the number of households in the EA as defined by the 2011 Population and Housing Census. 
The number of EAs selected in the sample was 297. At the second stage of sampling, the households were systematically selected using the list of occupied households prepared at the beginning of the study. The number of households that were drawn using systematic random sampling method was 5415. Fifteen households were selected per EA in urban areas, while 25 households were selected per EA in rural areas. The target population was at two levels: Biomarker or testing: all usual members of the selected households within the ages 6 weeks and above, and the Behavioural questionnaire: this segment targeted all usual members of the selected households aged 10 - 64 years old with age-appropriate questions.

The survey used Household and Individual questionnaires only. Both questionnaires were translated and administered in English or Setswana; while English is the official language of Botswana, Setswana is widely spoken across the country and may be the language of choice for some participants. The Individual Questionnaire was used to ask questions on all eligible individuals (aged 10 - 64 years) identified on the household questionnaire. As for the household questionnaire, the research assistant requested the individual, if adult, to consent to participate in the survey by answering the questionnaire put before him/her. Smartphones/tablets were used to collect data instead of using paper-based data collection methods. The questionnaire was uploaded into the Smartphone/tablet and data was transmitted via internet to the secure, password-protected server in Statistics Botswana. The SPSS computer programme was used in analyzing the data [19].

\section{Results}

Table 1 shows the demographic characteristics of the older adults (50 - 64 years) who had been diagnosed with TB infection ( $\mathrm{n}=12,052) ; 29.1 \%$ were aged 50 54; $55.7 \%$ aged 55 - 59 and $15.2 \%$ aged 60 - 64 years. The table reveals that $46.4 \%$ of older adults aged 50 - 54 years, $80.5 \%$ of those aged 55 - 59 years and $45.3 \%$ of those aged 60 - 64 years were males. Majority of the older adults were married. Over half of the older adults in all age groups were employed. Majority (over $90 \%$ ) of the older adults had either primary or no education. Prevalence rate of Asthma is very high among the older adults females aged 50 - 54 years (79.2\%) and those aged 60 - 64 years (67.8\%). Surprisingly, the original data showed no asthma disease among the males. High blood pressure/hypertension (23.3\%) and diabetes (31.6\%) were more predominant among those aged 55 - 59 years. Among the older adults who had TB, over eighty percent had been tested for HIV and of those who tested for HIV, over $40 \%$ acknowledged that they were HIV positive.

\subsection{HIV/AIDS Perception and Awareness by Older Adults}

In this section all the older adults $(50-64$ years $)(n=140,172)$ responded to some known conceptions and myths about HIV and AIDs, and its mode of 
Table 1. Demographic characteristics of the older adults $(50-64$ years) with TB (n = 12,052).

\begin{tabular}{|c|c|c|c|c|c|c|c|}
\hline & & \multicolumn{6}{|c|}{ Age of respondents } \\
\hline & & \multicolumn{2}{|c|}{$50-54$} & \multicolumn{2}{|c|}{$55-59$} & \multicolumn{2}{|c|}{$60-64$} \\
\hline & & Count & $\%$ & Count & $\%$ & Count & $\%$ \\
\hline \multirow{2}{*}{ Sex of the respondent } & Male & 1625 & 46.4 & 5409 & 80.5 & 829 & 45.3 \\
\hline & Female & 1881 & 53.6 & 1307 & 19.5 & 1001 & 54.7 \\
\hline \multirow{4}{*}{$\begin{array}{c}\text { Current } \\
\text { marital status }\end{array}$} & Total & 3506 & 100 & 6816 & 100 & 1830 & 100 \\
\hline & Married & 1535 & 43.8 & 3667 & 54.6 & 927 & 50.7 \\
\hline & Never married & 1181 & 33.7 & 2313 & 34.4 & 846 & 46.2 \\
\hline & $\begin{array}{c}\text { Separated, } \\
\text { divorced, widowed }\end{array}$ & 790 & 22.5 & 736 & 11 & 57 & 3.1 \\
\hline \multirow{3}{*}{ Employment Status } & Total & 3506 & 100 & 6716 & 100 & 1830 & 100 \\
\hline & Employed & 2337 & 66.7 & 4559 & 67.9 & 989 & 54.1 \\
\hline & Unemployed & 1169 & 33.3 & 2157 & 32.1 & 842 & 45.9 \\
\hline \multirow{4}{*}{$\begin{array}{l}\text { Highest } \\
\text { Educational } \\
\text { Level }\end{array}$} & None & 1559 & 44.5 & 5443 & 81.0 & 941 & 51.4 \\
\hline & Primary & 1704 & 48.6 & 735 & 11.0 & 889 & 48.6 \\
\hline & Secondary & 162 & 4.6 & 531 & 7.9 & 0 & 0 \\
\hline & Higher & 81 & 2.3 & 7 & 0.1 & 0 & 0 \\
\hline \multirow{4}{*}{$\begin{array}{c}\text { Have you ever been } \\
\text { diagnosed with asthma? }\end{array}$} & Total & 3506 & 100 & 6716 & 100 & 1830 & 100 \\
\hline & YES & 1489 & 79.2 & 75 & 5.8 & 678 & 67.8 \\
\hline & NO & 392 & 20.8 & 1232 & 94.2 & 323 & 32.2 \\
\hline & Total (only female) & 1881 & 100 & 1307 & 100 & 1001 & 100 \\
\hline \multirow{3}{*}{$\begin{array}{l}\text { Have you ever been } \\
\text { diagnosed with high blood } \\
\text { pressure/hypertension }\end{array}$} & YES & 451 & 12.9 & 1567 & 23.3 & 330 & 18 \\
\hline & NO & 3055 & 87.1 & 5149 & 76.7 & 1500 & 82 \\
\hline & Total & 3506 & 100 & 6716 & 100 & 1830 & 100 \\
\hline \multirow{3}{*}{$\begin{array}{c}\text { Have you ever been } \\
\text { diagnosed with diabetes? }\end{array}$} & YES & 439 & 12.5 & 2119 & 31.6 & 131 & 7.2 \\
\hline & NO & 3067 & 87.5 & 4597 & 68.4 & 1699 & 92.8 \\
\hline & Total & 3506 & 100 & 6716 & 100 & 1830 & 100 \\
\hline \multirow{3}{*}{$\begin{array}{l}\text { Have you ever been } \\
\text { tested for HIV, the } \\
\text { virus that causes AIDS? }\end{array}$} & YES & 3266 & 93.2 & 5989 & 89.2 & 1478 & 80.8 \\
\hline & NO & 240 & 6.8 & 727 & 10.8 & 352 & 19.2 \\
\hline & Total & 3506 & 100 & 6716 & 100 & 1830 & 100 \\
\hline \multirow{3}{*}{$\begin{array}{l}\text { What was the result } \\
\text { (answer if you } \\
\text { don't mind)? }\end{array}$} & POSITIVE & 1438 & 44.0 & 2432 & 40.6 & 1011 & 68.4 \\
\hline & NEGATIVE & 1828 & 56.0 & 3557 & 59.4 & 467 & 31.6 \\
\hline & Total & 3266 & 100 & 5989 & 100 & 1478 & 100 \\
\hline
\end{tabular}


contraction, treatment and prevention on a "Yes" and "No" basis. The results shown in Figure 1 and Figure 2 are the percentage of the "Yes" responses.

Figure 1 reveals that $97.9 \%$ of the older adults with TB agree that if a member of their family became sick with HIV and AIDS, they be willing to care for him or her in their household while $94 \%$ of them agree that if a teacher has HIV but is not sick, s/he should be allowed to continue teaching in school. Majority of them $(91.7 \%)$ have been tested for HIV. Over nine in every ten older adults with TB (91.2\%) strongly believe that if their housekeeper, Nanny or anybody looking after their child has HIV but is not sick, they would allow him/her to continue working or assisting with baby sitting in their house. However, only $83.9 \%$ of them are of the opinion that if they knew that a shopkeeper or food seller had HIV/AIDS, they would still buy vegetables from them while $76.5 \%$ would share a meal with a person they knew or suspected had HIV/AIDS. Yet only a little more than half of them (52.9\%) would want the HIV status of a member of their family who got infected with HIV to remain secret.

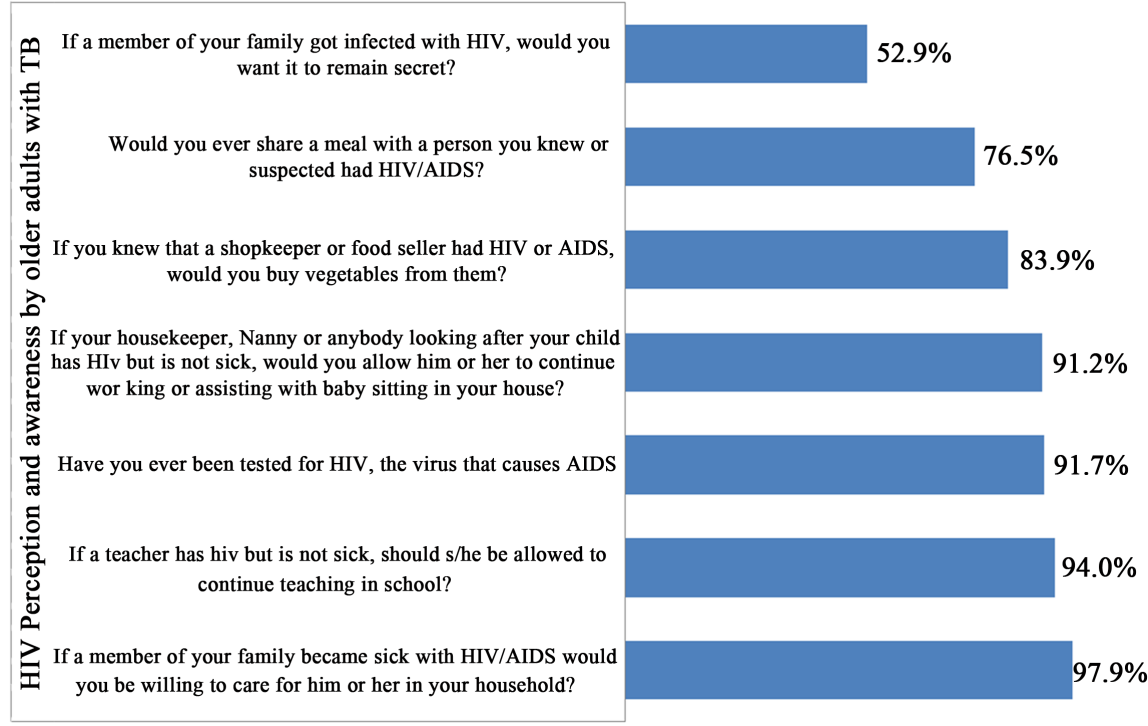

Figure 1. Perception and awareness of older adults about HIV.

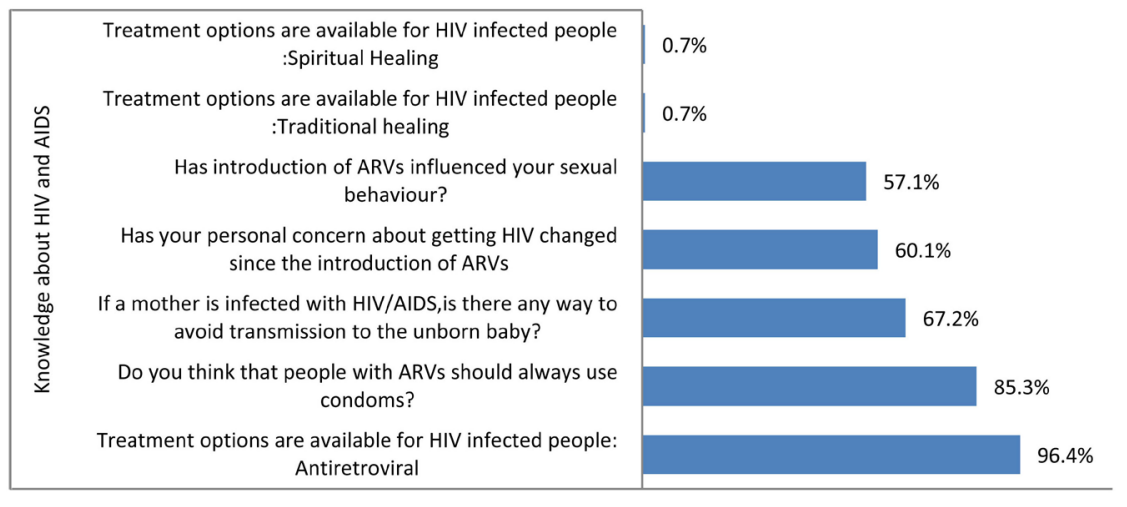

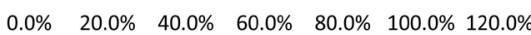

Figure 2. Older adults' knowledge of about ARV. 


\subsection{Knowledge of Usefulness of ARVs as Treatment for HIV}

On the knowledge of HIV and AIDS, $96.4 \%$ of the older adults have adequate knowledge that there is a treatment option for HIV using antiretroviral therapy (ART) while $85.3 \%$ know that people with HIV should use condoms whenever they want to have sex. Only $67.2 \%$ know that if a pregnant mother is infected with HIV, there is a way of preventing transmission of the virus to the child; only $60.1 \%$ have changed their personal concern about getting HIV since the introduction of ARV and 57.1\% have changed their sexual behaviour since introduction of ARV (Figure 2).

\subsection{Tuberculosis Diagnoses and Treatment}

The study shows that 22,304 of the older adults have HIV and $21.9 \%(\mathrm{n}=4874)$ are coinfected with TB. The older adults were asked the following questions: Have you ever been diagnosed with tuberculosis (TB) in the last 12 months before the study? Have you ever been treated for tuberculosis? And are you currently taking treatment for tuberculosis? The responses were $1=$ Yes and $2=$ No. Of the 140,172 older adults only 12,052 (8.6\%) (13\%, males and 5.3\%, females) had ever been diagnosed with tuberculosis; Of those who had been diagnosed, 8707 (6.2\%) had ever been treated for tuberculosis while only 1076 (0.8\%) were currently on treatment for TB.

\subsection{Sociodemographic Factors Affecting TB Treatment}

This section examines using the Logistic Regression Analysis how some socidemographic factors affect the treatment of TB in older adults. The dependent variable is: Have you ever been treated for TB? (Response: $1=$ Yes; $2=\mathrm{No}$ ). The independent variables are gender, employment status, HIV status, current marital status, highest educational qualification and age groups of the older adults. The results in Table 2 show that the males are significantly less likely to be treated for $\mathrm{TB}$ than the females $(\mathrm{OR}=0.274, \mathrm{p}<0.01$ ). The employed are significantly a little over 18 times more likely to be treated for TB than the unemployed. The older adults who are HIV positive are significantly more than 2.5 times more likely to be treated for TB than those who are HIV negative. The married and the never married are significantly 90.6 and 353.2 times, respectively, more likely to be treated for TB than the separated/divorced/widowed. Those who have secondary school level education are 2.5 times more likely to be treated for TB than those with higher level of education (e.g. Degree/Professional Certificate) while those with primary or no education are less likely to be treated for $\mathrm{TB}(\mathrm{OR}=0.032,0.033)$. The older adults who are $50-54$ and $55-59$ years old are significantly $(\mathrm{p}<0.01)$ less likely to be treated for $\mathrm{TB}(\mathrm{OR}<1)$ than those aged 60 - 64 years.

Furthermore, the results in Table 2 show that being male, having no or primary education, being 50 - 54 and 55 - 59 years old are significantly negatively correlated with being treated for TB $(\mathrm{B}<0 ; \mathrm{p}<0.05)$ whereas being employed, 
Table 2. Logistic regression analyses with dependent variable-you have been treated for TB.

\begin{tabular}{|c|c|c|c|c|c|c|c|c|c|}
\hline \multirow{2}{*}{$\begin{array}{l}\text { Reference } \\
\text { Category }\end{array}$} & \multirow{2}{*}{ Variables in the Equation } & \multirow{2}{*}{ B } & \multirow{2}{*}{ S.E. } & \multirow{2}{*}{ Wald } & \multirow{2}{*}{$\mathrm{df}$} & \multirow{2}{*}{ Sig. } & \multirow{2}{*}{$\operatorname{Exp}(B)$} & \multicolumn{2}{|c|}{$95 \%$ C. I. for $\operatorname{EXP}(B)$} \\
\hline & & & & & & & & Lower & Upper \\
\hline Female & Gender of the respondent (Male) & -1.295 & 0.094 & 191.831 & 1 & 0 & 0.274 & 0.228 & 0.329 \\
\hline Unemployed & Employment Status (Employed) & 2.897 & 0.1 & 841.672 & 1 & 0 & 18.126 & 14.903 & 22.045 \\
\hline HIV Negative & Result of HIV test (Positive) & 0.93 & 0.067 & 193.21 & 1 & 0 & 2.535 & 2.223 & 2.89 \\
\hline Separated/ & Current marital status & & & 715.076 & 2 & 0 & & & \\
\hline \multirow{3}{*}{$\begin{array}{l}\text { Divorced/ } \\
\text { Widowed }\end{array}$} & Married & 4.507 & 0.213 & 448.431 & 1 & 0 & 90.623 & 59.716 & 137.528 \\
\hline & Never married & 5.867 & 0.232 & 639.955 & 1 & 0 & 353.178 & 224.172 & 556.422 \\
\hline & Highest Educational Level & & & 455.694 & 3 & 0 & & & \\
\hline \multirow[t]{4}{*}{ Higher } & None & -3.403 & 0.533 & 40.718 & 1 & 0 & 0.033 & 0.012 & 0.095 \\
\hline & Primary & -3.435 & 0.534 & 41.397 & 1 & 0 & 0.032 & 0.011 & 0.092 \\
\hline & Secondary & 0.929 & 0.544 & 2.924 & 1 & 0.087 & 2.533 & 0.873 & 7.35 \\
\hline & Age of respondents & & & 555.81 & 2 & 0 & & & \\
\hline \multirow[t]{3}{*}{$60-64$} & $50-54$ & -0.389 & 0.093 & 17.555 & 1 & 0 & 0.678 & 0.565 & 0.813 \\
\hline & $55-59$ & -1.971 & 0.099 & 398.292 & 1 & 0 & 0.139 & 0.115 & 0.169 \\
\hline & Constant & -2.682 & 0.554 & 23.41 & 1 & 0 & 0.068 & & \\
\hline
\end{tabular}

HIV positive, married or never married are significantly positively correlated with being treated for $\mathrm{TB}(\mathrm{B}>0 ; \mathrm{p}<0.05)$.

\section{Discussion of the Results}

The results of this study show that the older adults with TB have very low educational attainment with over $91 \%$ having attained only primary education or no education at all. This result is very likely to affect the health seeking behaviour and health literacy of the older adults. Thobaben [20] shows that how much education one acquires affects the health literacy of the individual. The older adults have the greatest health literacy needs due to their high prevalence of chronic diseases. When people are unable to read or understand the words used to describe health problems, diagnostic tests, medications and directions for care, they might experience confusion in negotiating the health care system, and can be significantly handicapped in the tasks of self-care or caring for family members [21], [22]. It is important to improve the health education of older adults.

Although knowledge of the older adults about treatment of HIV and AIDS using ARV and prevention of HIV contraction by using condom during sex is high, their knowledge of mode of transmission, infection and utility of ARVs is poor. The results are in line with [23] who in their study on the perception older adults about sexuality found that $50 \%$ reported not having access to information on sexuality; $93 \%$ said they did not receive information about sexuality during their adolescence. Older adults need information on all possible modes of 
transmission and the specific ones that are high risk for their age group. In an era of HIV/TB coinfection, adequate knowledge of HIV and its symptoms will be essential to their detecting TB infection.

The results of this study show that among the older adults who had TB, over $90 \%$ had been tested for HIV and HIV prevalence in each age group is very high. These results are in line with those reported by [24] which shows that $60 \%-80 \%$ of patients with active TB in Botswana are co-infected with HIV and up to $40 \%$ of all HIV deaths are attributable to respiratory infections. These results are worrying and calls for specific intervention to check the excesses. It addresses the seriousness of ensuring that everyone diagnosed with TB need to be immediately tested for HIV and treatment commenced immediately [15].

Being employed, married or single and HIV positive are all significantly positively correlated with being treated for TB. The employed has more resources and are in most cases on Medical Aid. They are likely to have more information on their health status. They can therefore seek treatment for the disease. When someone is HIV positive, he/she is most likely to seeking test for TB and subsequently seeks treatment. Those who have primary education or no education are less likely to seek treatment for TB than those who have more than secondary education and are significantly negatively correlated with seeking treatment for TB. Thus the more informed about an ailment the more likely one would seek for the treatment. Hoa et al. [25] found out that educational level is an important determinant of people's level of knowledge of TB, and persons with a higher level of education scored better on TB knowledge indices than those with less education or those who were illiterate (see also [26]). Mondal et al. [26] showed that those individuals with higher education and are urban area patients were comparatively better informed about TB infection and that Education is significantly associated with health and makes a great impact on the enhancement on people's knowledge about TB. Males are proportionately more likely to be neglected in TB treatment, a result which agrees with [27] who found out that infectious diseases including Tuberculosis do not affect males and females equally while in a meta-analysis of 29 surveys conducted in 14 countries, it was found that there is a strong male bias in both notification rates and prevalence rates [28]. Women have been shown to have higher prevalence of HIV than males; the chances are that they are more likely to be diagnosed and treated with TB than the males. However, men have also been shown to be disproportionately disadvantaged when it comes to seeking or accessing TB care in a number of settings [28]. People with less education and consequently less knowledge of TB may likely not seek testing for TB even when the symptoms exist and therefore less likely to be diagnosed and treated with of TB [26]. Mondal et al. [26], stated that "delays in treatment of TB occur due to lack of knowledge, lack of awareness of the significance of symptoms, negative social attitudes or different combinations of these three factors and that patients with low knowledge about symptoms are less likely to seek healthcare". 


\section{Conclusion}

The study has therefore shown that older adults in Botswana aged 50 - 64 years living with TB have low educational qualifications (over 91\%-Primary and no education in all age groups), very high HIV prevalence (40.5\%) and low knowledge that if a pregnant mother is infected with HIV, there is a way of preventing transmission of the virus to the child (67.2\%). Thus, lower education seems to be an obstacle to accessing TB treatment. It is important that older adults' awareness and knowledge of the symptoms of both diseases, mode of infection and treatment are adequately improved. This can be accomplished through increased education to overcome health challenges when infected with asthma, diabetes and high blood pressure/hypertension.

\section{Conflicts of Interest}

The authors declare no conflicts of interest regarding the publication of this paper.

\section{References}

[1] Corbett, E.L., Watt, C.J., Walker, N., Maher, D., Williams, B.G., et al. (2003) The Growing Burden of Tuberculosis: Global Trends and Interactions with the HIV Epidemic. Archives of Internal Medicine, 163, 1009-1021.

https://doi.org/10.1001/archinte.163.9.1009

[2] Getahun, H., Gunneberg, C., Granich, R. and Nunn, P. (2010) HIV Infection-Associated Tuberculosis: The Epidemiology and the Response. Clinical Infectious Diseases, 50, S201-S207. https://doi.org/10.1086/651492

[3] Collins, K.R., Quinones-Mateu, M.E., Toossi, Z. and Arts, E.J. (2002) Impact of Tuberculosis on HIV-1 Replication, Diversity, and Disease Progression. AIDS Reviews, 4, 165-176.

[4] WHO (2019) TB and HIV 2019. https://www.who.int/tb/areas-of-work/tb-hiv/en/

[5] WHO (2011) Global Status Report on Noncommunicable Diseases 2010. Italy: World Health Organization.

[6] Ayah, R., Joshi, M.D., Wanjiru, R., Njau, E.K., Otieno, C.F., Njeru, E.K. and Mutai, K.K. (2013) A Population-Based Survey of Prevalence of Diabetes and Correlates in an Urban Slum Community in Nairobi, Kenya. BMC Public Health, 13, 371. https://doi.org/10.1186/1471-2458-13-371

[7] Mbanya, J.C., Motala, A.A., Sobngwi, E., Assah, F.K. and Enoru, S.T. (2010) Diabetes in Sub-Saharan Africa. The Lancet, 375, 2254-2266. https://doi.org/10.1016/S0140-6736(10)60550-8

[8] Global Asthma Network (2014) The Global Asthma Report 2014. http://www.globalasthmanetwork.org/publications/Global Asthma Report 2014.p df

[9] Tarraf, H., Aydin, O., Mungan, D., Albader, M., Mahboub, B., Doble, A., Lahlou, A., Tariq, L., Aziz, F. and Hasnaoui, A.E. (2018) Prevalence of Asthma among the Adult General Population of Five Middle Eastern Countries: Results of the SNAPSHOT Program. BMC Pulmonary Medicine, 18, 68. https://doi.org/10.1186/s12890-018-0621-9 
[10] Bramlage, P. and Hasford, J. (2009) Blood Pressure Reduction, Persistence and Costs in the Evaluation of Antihypertensive Drug Treatment-A Review. Cardiovascular Diabetology, 8, 18. https://doi.org/10.1186/1475-2840-8-18

[11] Mozaffarian, D., Benjamin, E.J., Go, A.S., Arnett, D.K., Blaha, M.J., Cushman, M., de Ferranti, S., Despres, J.P., Fullerton, H.J., Howard, V.J., Huffman, M.D., Judd, S.E., Kissela, B.M., Lackland, D.T., Lichtman, J.H., Lisabeth, L.D., Liu, S., Mackey, R.H., Matchar, D.B., McGuire, D.K., Mohler, E.R., Moy, C.S., Muntner, P., Mussolino, M.E., Nasir, K., Neumar, R.W., Nichol, G., Palaniappan, L., Pandey, D.K., Reeves, M.J., Rodriguez, C.J., Sorlie, P.D., Stein, J., Towfighi, A., Turan, T.N., Virani, S.S., Willey, J.Z., Woo, D., Yeh, R.W., Turner, M.B. (2015) Heart Disease and Stroke Statistics-2015 Update: A Report from the American Heart Association. Circulation, 131, 434-441. https://doi.org/10.1161/CIR.0000000000000157

[12] Mitka, M. (2010) IOM Urges More Attention by Physicians, Public on "Neglected" Hypertension. JAMA: The Journal of the American Medical Association, 303, 1354-1355.

[13] WHO (2018) Leave No One behind: Scaling Up Integrated People-Centred TB/HIV care towards Universal Health Coverage, UN High Level Meeting on TB, 26 September 2018.

[14] CDC (2018) HIV and Tuberculosis. Division of HIV/AIDS Prevention, National Center for HIV/AIDS, Viral Hepatitis, STD, and TB Prevention. Centers for Disease Control and Prevention.

[15] Tshitenge, S., Ogunbanjo, G.A. and Citeya, A. (2018) A Mortality Review of Tuberculosis and HIV Co-Infected Patients in Mahalapye, Botswana: Does Cotrimoxazole Preventive Therapy and/or Antiretroviral Therapy Protect against Death? African Journal of Primary Health Care \& Family Medicine, 10, a1765. https://doi.org/10.4102/phcfm.v10i1.1765

[16] Yoshikawa, T.T. (1992) Tuberculosis in Aging Adults. Journal of the American Geriatrics Society, 40, 178-187. https://doi.org/10.1111/j.1532-5415.1992.tb01941.x

[17] Pratt, R.H., Winston, C.A., Kammerer, J.S. and Armstrong, L.R. (2011) Tuberculosis in Older Adults in the United States, 1993-2008. Journal of the American Geriatrics Society, 59, 851-857. https://doi.org/10.1111/j.1532-5415.2011.03369.x

[18] Perez-Guzman, C., Vargas, M.H., Torres-Cruz, A. and Villarreal-Velarde, H. (1999) Does Aging Modifypulmonary Tuberculosis? A Meta-Analytical Review. Chest, 116, 961-967. https://doi.org/10.1378/chest.116.4.961

[19] Statistics Botswana (2013) Botswana AIDS Impact Survey IV 2013 Statistical Report. Gaborone, Botswana.

[20] Thobaben, M. (2007) Health Literacy and Elderly Home Health Clients. Home Health Care Management \& Practice, 19, 478-479. https://doi.org/10.1177/1084822307304250

[21] Parker, R. (2000) Health Literacy: A Challenge for American Patients and Their Health Care Providers. Health Promotion International, 15, 277-283. https://doi.org/10.1093/heapro/15.4.277

[22] Nielsen-Bohlman, L., Panzer, A.M. and Kindig, D.A. (2003) Health Literacy: A Prescription to End Confusion. National Academy of Sciences, Washington DC.

[23] Frugoli, A. and de Oliveira, C.A. (2015) Sexuality in Third Age in the Perception of a Female Elderly Group and Indications for the Environmental Education. https://www.semanticscholar.org/paper/Sexuality-in-third-age-in-the-perception-of -a-group-Frugoli-J\%C3\%BAnior/846289aecc571b4fb989f108bb00548c4f3b37af 
[24] Ministry of Health Botswana TB/HIV Collaborative Policy Guidelines, Gaborone. http://www.tbonline.info/media/uploads/documents/botswana tb:hiv policy guide lines \%282011\%29.pdf

[25] Hoa, N.P., Diwan, V.K. and Co, N.V. (2004) Thorson AEK: Knowledge about Tuberculosis and Its Treatment among New Pulmonary TB Patients in the North and Central Regions of Vietnam. International Journal of Tuberculosis and Lung Disease, 8, 603-608.

[26] Mondal, M.N.I., Nazrul, H.M., Chowdhury, M.R.K. and Howard, J. (2014) Socio-Demographic Factors Affecting Knowledge Level of Tuberculosis Patients in Rajshahi City, Bangladesh. African Health Sciences, 14, 855-861. https://doi.org/10.4314/ahs.v14i4.13

[27] Guerra-Silveira, F. and Abad-Franch, F. (2013) Sex Bias in Infectious Disease Epidemiology: Patterns and Processes. PLoS ONE, 8, e62390.

https://doi.org/10.1371/journal.pone.0062390

[28] Borgdorff, M.W., Nagelkerke, N.J., Dye, C. and Nunn, P. (2000) Gender and Tuberculosis: A Comparison of Prevalence Surveys with Notification Data to Explore Sex Differences in Case Detection. International Journal of Tuberculosis and Lung Disease, 4, 123-132. 